\title{
Hacia un modelo de narrativa en periodismo inmersivo
}

\section{Towards a model of narrative in immersive journalism}

Raquel Caerols Mateo. Universidad Francisco de Vitoria. España. r.caerols.prof@ufv.es

$[\underline{\mathrm{CV}}]$ (1) $\mathrm{G}$

Pavel Sidorenko Bautista. Universidad de Castilla-La Mancha. España.

Pavel.Sidorenko@alu.uclm.es

$[\underline{\mathrm{CV}}]$ (1) $\mathrm{G}$

Pablo Garrido Pintado. Universidad Francisco de Vitoria. España.

p.garrido.prof@ufv.es

$[\underline{\mathrm{CV}}]$ (1) G

Cómo citar este artículo / Referencia normalizada

Caerols Mateo, R., Sidorenko Bautista, P. y Garrido Pintado, P. (2020). Hacia un modelo de narrativa en periodismo inmersivo. Revista Latina de Comunicación Social, 75, 341-365. https://www.doi.org/10.4185/RLCS-2020-1430

\section{RESUMEN}

Introducción: Ante el incremento de uso por parte de periodistas y medios de comunicación, de la realidad virtual y los contenidos inmersivos como formato para informar, nos hemos propuesto aportar un posible modelo de narrativa de realidad virtual para la producción de estos contenidos. Metodología: Se ha optado por un estudio mixto, donde lo cuantitativo está compuesto por encuestas realizadas a 60 individuos Generación $Z$ españoles, al tiempo que dos grupos de discusión con 5-6 individuos de similar grupo etario. Asimismo, se consideró un análisis comparativo entre elementos de la narrativa inmersiva y la narrativa audiovisual tradicional, para alcanzar el fin deseado. Resultados y conclusiones: se evidencia la complejidad de la segmentación de audiencias en el ámbito digital, aunque los individuos pertenezcan al mismo entorno social. Los instrumentos de medición permitieron disponer de algunos elementos básicos para la creación de contenidos noticiosos en formatos multimedia con capacidad inmersiva, los cuales deben ir acompañados de un compromiso y constancia por parte de los medios de comunicación y periodistas implicados en procesos de innovación.

PALABRAS CLAVE: periodismo inmersivo; modelo narrativo; producción; realidad virtual; Generación Z; España.

\begin{abstract}
Introduction: Given the increase in use of virtual reality and immersive content as a reporting format by journalists and the media, we have proposed a possible virtual reality narrative model for the production of these types of content. Method: We have opted for a mixed study, where the quantitative is made up of surveys conducted with 60 Generation Z Spaniards, at the same time as
\end{abstract}


two discussion groups, with 5-6 individuals of a similar age. Likewise, a comparative analysis is considered between elements of the immersive narrative and the traditional audio-visual narrative in order to reach the desired end result. Results and conclusions: The complexity of the segmentation of audiences in the digital field is evident, despite the individuals belonging to the same social environment. The instruments of measurement allow for some basic elements for the creation of news content in multimedia formats with immersive capacity, which should be accompanied by commitment and perseverance by the media experts and journalists involved in the innovation processes.

KEYWORDS: immersive journalism; narrative model; production; virtual reality; Generation Z; Spain.

\section{CONTENIDO}

1. Introducción. 2. Marco Teórico y estado de la cuestión. 2.1. Realidad virtual y contenidos multimedia con capacidad inmersiva. 2.2. Periodismo, realidad virtual y formatos multimedia con capacidad inmersiva. 3. Objetivos e Hipótesis. 4. Metodología. 5. Resultados. 6. Discusión y conclusiones. 7. Referencias bibliográficas.

\section{Introducción}

La expansión de internet a todos los rincones del planeta y la articulación de sus lenguajes y sus reglas del juego cada vez más perfeccionados y asentados, así como la imbricación del lenguaje binario y sus algoritmos en el quehacer humano, y en la génesis del mismo en el contexto de la llamada Cuarta Revolución Industrial (Schwab, 2016), se está produciendo un cambio abrupto y profundo en una sociedad globalizada.

Este contexto, en relación a lo referenciado, tiene una repercusión directa en todos los ámbitos del saber, y el de la comunicación y, específicamente, el del periodismo -que es nuestro campo de acción en la presente investigación-, no queda fuera.

Tal es el caso, que los hábitos de consumo de contenidos e información están determinados, prácticamente a totalidad, por las tecnologías móviles. Una situación que ha generado la necesidad de crear y desarrollar nuevos contenidos y nuevas narrativas para dar respuesta a las múltiples plataformas del contexto digital y que nos ha llevado a dichas formas de consumo, situándonos ante la posibilidad de desarrollar nuevas alternativas para contar y hacer coberturas de los acontecimientos.

En este sentido, por el carácter emergente y de permanente transformación del hábitat digital, la única dinámica posible es la de la experimentación, donde todos los actores implicados y los nuevos que surgen por la necesidad del contexto, se encuentran desarrollando propuestas múltiples y muy diversas, sin una línea de trabajo común en la creación de nuevos contenidos y en la forma de narrarlos dentro de las posibilidades del lenguaje y las tecnologías digitales.

Así, los formatos multimedia con capacidad inmersiva y la realidad virtual se muestran como una clara alternativa informativa interactiva, que apunta a que la audiencia se involucre más con lo que ve, posibilitando con ello, inclusive, una mayor empatización dado que la posiciona en primera persona frente al contenido.

Pero como bien indicamos, la experimentación que aún impera en este aspecto, pese a que el formato resucitara en un ya lejano 2014, va requiriendo de un estándar, unas normas narrativas definidas para 
la creación de contenidos que pretendan obtener resultados positivos de aceptación e interacción por parte de la audiencia, que se inserte en su cotidianidad, en sus formas de leer, ver, mirar y entender la realidad que les rodea.

De los experimentos realizados por Hendriks et al. (2019) y Shin y Biocca (2018) queda sentenciado que esta tecnología y sus formatos derivados resultan altamente positivos en la comprensión e implicación de la audiencia con temas abordados a través de ellos.

Es por ello que, a partir de la experiencia y opiniones de un número determinado de usuarios pertenecientes a la Generación $Z$ (Turner, 2015) -la próxima e inmediata generación de consumoespañola, el objetivo de esta investigación se centra en delimitar unos criterios básicos narrativos en la cobertura informativa, a partir de formatos multimedia en $360^{\circ}$ con capacidad inmersiva.

Disponemos de la tecnología para generar modelos narrativos periodísticos inmersivos en $360^{\circ}$, pero no aún de un modelo de narrativa consensuado por los expertos para los formatos multimedia en este sentido, como sí existe en la narrativa audiovisual tradicional de la televisión y el cine, por ejemplo. Hay muchas propuestas, pero no normatizadas, sistematizadas o estandarizadas, al tiempo que perdura la experimentación y la irregularidad en la búsqueda de ello, lo cual incide negativamente en el desarrollo del formato y en el asentamiento de los hábitos de consumo.

\section{Marco teórico y estado de la cuestión}

La denominada Cuarta Revolución Industrial ha llegado, somos parte de ella. Un proceso que define Schwab (2016) como una confluencia en veloz y profunda transformación, de una sociedad altamente interconectada a través de las tecnologías móviles, el desarrollo de la nano y la biotecnología, el indiscutible avance de la inteligencia artificial (AI), así como la consolidación de la internet de las cosas (IoT), entre otros procesos, en su mayoría o todos ligados al ámbito tecnológico.

Este escenario favorece el desarrollo de la ubicuidad informativa, gracias a las conexiones $5 \mathrm{G}$ y redes más seguras a través de los sistemas Blockchain (Salaverría, 2018).

Un contexto donde resulta evidente un cambio en el patrón con el que la sociedad enfrenta diversos retos, trata con la información y construye diversos niveles de relación. Al respecto, para Calvo (2018) justamente asistimos a un nuevo condicionamiento de las relaciones interpersonales, así como en las colectivas, como consecuencia de la digitalización.

Son diversos los ámbitos de la vida humana que se ven impactados por esta situación y que se encuentran en constante evolución producto de ello. Tanto las comunicaciones, como el periodismo en específico, son de las áreas que tienen un fuerte y estrecho condicionamiento con este proceso.

Esta digitalización y el veloz avance de las tecnologías han ocasionado que el periodismo se redefina en algunos aspectos, permitiendo la creación de nuevos roles como: Director de 'engagement' de audiencia, reportero de noticias en redes sociales, productor de vídeos en Snapchat (Glickhouse, 2018).

Queda así en evidencia la hegemonía que ostenta hoy internet y sus diversas posibilidades digitales a la hora de comunicar, frente a los medios tradicionales. Las redes sociales han llevado a un nivel muy alto ese principio prosumidor que ya Toffler describía hacia 1980: el público ha abandonado su pasividad, para ser copartícipes del proceso informativo. Por tanto, pareciera que queda abolida la frase de McLuhan de "el medio es el mensaje" para dar pie a "el pueblo es el mensaje" (Cardoso, 2014). 
Una advertencia que comparten Calvo (2018) y Noguera (2018) cuando afirman que las redes sociales en particular, permiten que las personas gocen de un rol destacado en la comunicación colectiva -e inclusive y con más frecuencia, efímera-, lo cual sustenta el argumento de Castells (2010) de la "autocomunicación de masas".

Esta audiencia, con especial énfasis en las llamadas Generación $Y$ (Millennials) y Generación $Z^{1}$ (Turner, 2015), es cada vez más demandante de contenidos multimedia que proporcionen mayores niveles de interactividad. Vale destacar que, en parte, esto es consecuencia de la penetración de las tecnologías móviles, y muy en especial del constante uso que hacemos de los smartphones (Kakihara, 2003; Sørensen, 2003).

Para Feixa, Fernández-Planells y Figueras-Maz (2016) en contraposición, estas generaciones hiperdigitales e interconectadas son consideradas como Generación @ y Generación \#. La primera porque responde a la introducción y desarrollo de internet y la segunda, a esa cultura colaborativa en red. En resumen, corresponde al mismo proceso descrito.

Por tanto, la movilidad es considerada como un nuevo paradigma para la informática, así como también para las sociedades, las cuales son reconocidas hoy día como nómadas o móviles (Giddens, 1999; Hjelm, 2000; Urry, 2000).

De esta manera resulta cada vez mayor la demanda de generación de nuevos contenidos, que dé respuesta a las nuevas vías para consumirlos y publicarlos. Vemos cómo surgen diversos elementos complementarios de las palabras como los emoji, los stickers y los GIF. Asimismo, nuevas maneras estéticas en lo audiovisual, signadas por la temporalidad impuesta en las "historias" de Snapchat e Instagram.

Pero como ya indicamos, las audiencias se encuentran cada vez más segmentadas, y en esta diversidad en la demanda de formatos, surgen como alternativas audiovisuales, la realidad aumentada, la realidad mixta, la realidad virtual y los vídeos y fotografías en $180^{\circ}$ y $360^{\circ}$ con capacidad inmersiva.

Sobre los tres últimos, vale destacar que se trata de un fenómeno sobre el cual diferentes consultoras y encuestadoras indican que su desarrollo alcanzará el punto determinante entre 2020-2023, momento en el que será considerada una tecnología de uso común para la mayoría de las personas (Deloitte http://bit.ly/2eXhZX6, Statista http://bit.ly/2iaS5Tw, Business Insider http://bit.ly/2Bh5f5z).

\subsection{Realidad virtual y contenidos multimedia con capacidad inmersiva}

Cuando hacemos referencia a estos términos, por el carácter emergente de los mismos y, por ello, en proceso de su propia definición y conceptualización (que se va generando entre todos en la propia materialización y formas de consumo de los mismos), diversos autores y divulgadores en la materia, no evidencian una clara diferenciación de los formatos de carácter inmersivos, mostrándolos y

\footnotetext{
${ }^{1}$ La "Generación Z” representa al día de hoy el mayor segmento de consumo audiovisual en internet, como ya quedaba claro en 2016, en las cifras publicadas por la propia plataforma YouTube, la cual ubicó a esta audiencia en el 81,9\% de sus usuarios en Estados Unidos (véase http://bit.ly/2AxzTcO). Como bien indica Turner (2015) nos referimos a la generación que ha nacido con internet, que no conoce y no concibe el mundo sin la interconexión actual y, por ende, son considerados nativos digitales o net-gen.

Sobre esta estratificación, es conveniente revisar por igual los trabajos y estudios realizados por la propia plataforma YouTube (http://bit.ly/2AxzTcO) o por la Fundación Telefónica (https://www.youtube.com/watch?v=YHSvkWseOdY).
} 
definiéndolos como símiles, cuando ciertas determinaciones técnicas marcan clasificación diferencial.

Por tanto, la realidad virtual la definiremos como aquella experiencia interactiva e inmersiva a través de la cual el usuario obtiene la sensación de encontrarse en un lugar determinado, mediante el uso de un dispositivo con pantalla ubicado en la cabeza, el cual da acceso a una interfaz digital que permite alcanzar sensaciones emocionales e inclusive físicas similares a las de la vida real (Ryan citado en Vásquez y López, 2017; Sidorenko, Cantero y Herranz, 2017).

En palabras de Slater (2009) es la ilusión de que algo está pasando en verdad.

Los más puristas en el aspecto tecnológico (De la Peña, 2010; Pavlik, 2001; Pryor, 2000) establecen que la verdadera realidad virtual y la verdadera inmersión corresponden a experiencias donde intervengan gadgets que permitan no solo un libre albedrío en la experiencia del visionado, sino también interacción por parte de nuestras extremidades. Hablamos de casos como los visores Oculus Rift, Oculus Quest, HTC Vive (todos sus modelos) y Lenovo Mirage, que incluyen elementos que comprometen los movimientos de nuestras manos.

A esta experiencia se le ha otorgado la denominación técnica de $6 D o F$, siglas que en inglés (six degrees of freedom) se refieren a los 6 grados de libertad que se alcanzan -de momento- a través de dichos dispositivos.

No obstante, pese a que esta tecnología y el desarrollo de los formatos se retomaron con firmeza a partir de 2014, principalmente por responsabilidad de Google y Facebook, como ya anticipamos, al día de hoy aún no existe consenso sobre diversos conceptos derivados de este proceso.

Por un lado, debemos establecer que la inmersión -principio básico de esta tecnología- es la posibilidad que tiene el usuario alcanzar la sensación de estar en el lugar representado más que en el espacio físico real donde se encuentra realmente (Mütterlein, 2018; Sánchez- Vives y Slater, 2005).

Asimismo, de acuerdo a las características de los contenidos, Sidorenko et al (2017) establecen una diferenciación importante. A su criterio, existe por un lado la Realidad Virtual Virtual (RV2), compuesta por los contenidos producidos a través de software especial de diseño en 3D y plataformas como Unity y Unreal; y por otro lado, la Realidad Virtual Real (RVR), que se refiere a los contenidos con capacidad inmersiva obtenidos a partir de experiencias reales, a través de equipos de grabación especiales, tales como Samsung Gear, Insta360 nano o air, Xiaomi Miji Mi Sphere, solo por citar algunos ejemplos referenciales.

\subsection{Periodismo, realidad virtual y formatos multimedia con capacidad inmersiva}

A la imbricación entre el periodismo y las tecnologías con capacidad de proporcionar inmersión a partir de fotos y vídeos, se ha denominado "Periodismo inmersivo" (De la Peña, 2010; Domínguez, 2010).

Si bien en un principio fue planteado como un concepto que describía la posibilidad que tenía la audiencia de alcanzar una gran implicación con la información consumida, así como establecer un mayor nivel de empatía, su última acepción alude al hecho de desarrollar contenidos noticiosos en formato con capacidad inmersiva, con el fin de ser consumidos a través de visores de realidad virtual (Cantero et al., 2018). 
Esta última acepción no dista radicalmente de la consideración inicial, cuando Kishore (citado en Shin y Biocca, 2018) afirma que el encuentro de las industrias periodísticas y tecnológicas por medio de la realidad virtual, ha permitido mejorar la experiencia del usuario con la noticia, porque a mayor inmersión, mayor implicación por parte de este.

En resumen, se trata de una propuesta narrativa que pretende aumentar la capacidad de inmersión de la audiencia, apuntando a la interacción, con lo cual, la interfaz, la calidad del contenido y el relato deben estar estrechamente relacionados, con la principal intención de posicionar en primera persona al usuario con respecto a lo que está viendo (Domínguez, 2010).

La inmersión en periodismo se consigue cuando el usuario tiene la posibilidad de interactuar con la noticia, con los elementos de su historia o los datos. Con esto, en lugar de leer, la audiencia se involucra con el contenido, teniendo la posibilidad de alcanzar una mayor comprensión del tema (Steve Outing citado por Pérez-Seijó, 2016, p. 404).

Y es que el periodismo está hecho de eso, de historias y, por tanto, la propuesta inmersiva al igual que otras formas de hacer periodismo, trata de narrativa, donde los datos y la información constituyen un relato (Pontes y Silva, 2010). En definitiva, el periodismo es una narración, un relato constituido por eventos correspondientes a una acción temporal que estimula la imaginación (Motta, 2005).

De allí que hagamos énfasis en que el periodismo articulado a través de esta nueva tecnología, centra su apuesta en involucrar en mayor medida a la audiencia con respecto al contenido propuesto, condición ésta, que ya ha quedado en evidencia en estudios exploratorios como el de Wytt et al. (2016). Por tanto, Ahn y Shin (citados en Shin y Biocca, 2018) sostienen que tanto empatía, como encarnación o posicionamiento en primera persona, son conceptos intrínsecos de la realidad virtual como de su necesidad por construir una historia (storytelling).

En algún momento Manfredi (2004) destacaba la importancia de los medios públicos, en especial la $\mathrm{TV}$, en su rol educador, al servicio de los ciudadanos. Este formato permite retomar este rol que define a un medio/periodista como paternalista, que inculta valores y refuerza el perfil del ciudadano, dada su importante papel empatizador y sensibilizador.

En definitiva, asistimos con esto a la ruptura de la cuarta pared representada en la pantalla de los dispositivos, que previo a esta alternativa audiovisual, actuaba como separación entre audiencia y el relato noticioso (Pérez-Seijó et al., 2018, Longui, 2016, Domínguez, 2013).

Para la editora adjunta de vídeo y codirectora de realidad virtual de The New York Times, Marcelle Hopkins (2017), el periodismo inmersivo es el único que al día de hoy permite llevar a la audiencia a lugares a los que no resulta acceder o bien por vías convencionales, o bien con las posibilidades económicas y de tiempo con las que cuenta la mayoría de las personas, al tiempo de hacerlos sentir en el lugar con el fin de alcanzar experiencias físicas similares a las reales, todo al mismo tiempo.

La pretensión final, como señalan Paíno et al. (2016) y De la Peña (2010) es conseguir que el usuario se vea representado en un avatar digital que penetra en el escenario virtual de la historia noticiosa.

Es criterio de Domínguez (2013), que las fotografías en $360^{\circ}$ con capacidad inmersiva no permiten alcanzar una plena conexión inmersiva entre la audiencia y el contenido como sí ocurre con los vídeos con similar característica, dado que la pantalla actúa como cuarta pared, diferenciando el mundo físico y el que se representa en el relato en cuestión. Aspectos como el audio también resultan primordiales, a fin de conseguir abstracción entre los dos planos en cuestión. 
Como casos aventajados a nivel mundial en el desarrollo de plataformas, propuestas narrativas y producción de contenidos enfocados en la posibilidad inmersiva, tenemos: The New York Times, The Washington Post, USA Today, ABC News, Euronews, BBC, The Guardian, CNN, DW, El País $y$ RTVE.

Estamos en un contexto donde todo nuevo producto digital se distancia cada vez más de una mera adaptación de las ediciones impresas, lo cual incide en que los periodistas tengan más libertad para dar forma, cambiar y mejorar sus productos, y sobre todo, innovar. Así, podemos ver una mejoría en la diversidad de las narrativas y las técnicas periodísticas (Manfredi y Artero, 2014).

El primer diario en explotar el recurso de la realidad virtual para formalizar la actual acepción del periodismo inmersivo fue el estadounidense The Des Moines Register (Grupo USA Today) en 2015 (http://bit.ly/2Sap2MK). Con el título "Harvest of Change", el tema planteado fue, a partir del caso de la granja de la familia Dammann, exponer cómo el cambio demográfico y económico en Estados Unidos afecta directamente a las familias agrícolas de Iowa.

Mediante una réplica de la granja de esta familia y a partir de software de diseño en 3D, gracias al principio $6 \mathrm{DoF}$ que permiten los visores Oculus Rift, los usuarios pueden realizar un recorrido por las instalaciones del recinto, dotándolos de la posibilidad de conocer diferentes aspectos de su rutina de trabajo, así como personales. Existen diferentes puntos de atención relacionados con espacios específicos dentro de la locación que, al interactuar con ellos, nos remiten a experiencias en formato $\mathrm{RVR}$, donde la interacción solo se limita al visionado en $360^{\circ}$ en lo vertical y horizontal.

En estos contenidos hay la posibilidad de estar ante un periodista conversando con miembros de la familia sobre aspectos inherentes a la dinámica comercial con el pueblo donde ésta familia hace vida, así como presenciar momentos más personales como la misa de domingo, o acompañar al padre de familia en su tractor junto a su hijo a realizar el arado de los terrenos.

No existen elementos explicativos adicionales como textos o imágenes, más allá de una narración en off intermitente. Solo existen textos explicativos en el modo de experiencia RV2 6DoF, donde algunos puntos de atención complementan lo que vemos, mediante fichas técnicas de equipos relacionados con la dinámica de la granja, estadísticas sobre el movimiento comercial de algunos productos agrícolas o breves descripciones de aspectos característicos de un entorno como el que venimos describiendo.

Se trata, en resumidas, de una propuesta innovadora donde quedan imbricadas las dos estéticas a la hora de realizar periodismo inmersivo, es decir, RV2 y RVR, con lo cual se intenta conseguir mayor implicación de la audiencia al proporcionarle mayores elementos de interacción.

Resulta necesario acotar que estos equipos de consumo de realidad virtual, como también son las HTC Vive, resultan muy costosas porque pese al precio mayor que ya implican por sí solas en comparación con otro tipo de visores, requieren de un equipo informático con características de vídeo y procesamiento de datos muy altas, con lo cual el número de usuarios que disponen de ellas en sus hogares es muy reducido. No obstante, consideraciones al respecto, formarían parte de otro tipo de análisis que no corresponde a los fines particulares de esta investigación.

El siguiente medio en dar pasos sólidos en el recurso de los contenidos inmersivos para informar a su audiencia, fue otro medio estadounidense: The New York Times, por igual en 2015. Pero su estrategia y uso de esta tecnología fue diferente. 
Como se desprende del reportaje de Marcelle Hopkins en el propio medio (https://nyti.ms/2V3cvN5) fue en noviembre de ese año que para promocionar y dar a conocer su primer documental inmersivo "The Displaced" (sobre los niños desplazados por las guerras) y la app móvil "NYT VR", este diario neoyorquino distribuyó 1 millón de visores del tipo "cardboard" a sus suscriptores. Desde entonces, más de una veintena de documentales en este formato han seguido a esta "ópera prima" con el fin de generar mayor acercamiento por parte de la audiencia, hacia temas sensibles y complejos que copan la actualidad noticiosa del mundo.

Una gran receptividad que los llevó a materializar "The Daily 360", el portal mediante el cual The New York Times se ha comprometido a publicar al menos un vídeo diario con capacidad inmersiva, sobre diversas temáticas que aluden a la actualidad tanto norteamericana como mundial.

Después de estas primeras manifestaciones, como ya hemos mencionado, se han venido consolidando otras propuestas en el mismo campo, quedando en evidencia un despliegue irregular de esta tecnología en lo relativo al tipo de medio, las narrativas y formatos desarrollados por el mismo, así como por el ámbito geográfico en el que se desenvuelve, lo que ha complejizado en gran parte la conformación de unos criterios básicos para la producción informativa y periodística a través de estos recursos.

Para el caso específico de España, si bien muchos medios se han sentido seducidos por incluir este recurso tecnológico en la cobertura noticiosa -algunos impulsados por la sensación de "novedad" y/o "moda", así como otros por la necesidad de incluir elementos innovadores en su oferta-, lo cierto es que son pocos los que mantienen una constancia hasta hoy en la producción de contenidos en este sentido.

De aproximadamente 23 que podemos identificar a priori: Agencia EFE, Antena 3 Noticias, El Español, MARCA, El Confidencial, AS, Canal de Extremadura, Diario de Navarra, SUR, Diario de Sevilla, 8 Zamora, TV3, El Diario Montañés, Televisió de les Illes Balears, Faro de Vigo, CRTVG, Radio Televisión de Castilla y León, La Vanguardia, RTVE, El País, El Diario Conquense, El Deporte Conquense, Castilla-La Mancha Media, son los últimos cinco los que mantienen en el tiempo este tipo de producciones, constituyéndose ya en un elemento formal en su oferta informativa.

\section{Objetivos e hipótesis}

Partiendo del hecho de que la realidad virtual y los formatos multimedia con capacidad inmersiva generan mayor interés y vinculación de la audiencia, esencialmente con determinados temas, como se desprende de experimentos como los de Shin y Biocca (2018) o de Steed et al. (2018), la principal pretensión de esta investigación es contribuir, por consiguiente, a una aproximación de un modelo o propuesta estándar narrativa para la creación de contenidos multimedia con capacidad inmersiva en el ámbito del periodismo.

Por ello, para avanzar en lo señalado, resulta pertinente aportar a la comunidad científica, académica y profesional, una muestra de experiencias y gustos de consumo por parte de las audiencias jóvenes (Generación Z- según el concepto y argumento de Turner (2015) en España, quienes empiezan ya a ser los consumidores de este tipo de contenidos, y que en un futuro próximo serán el grueso de las audiencias de estos y otros formatos derivados del desarrollo digital.

A partir de ello, nos planteamos las siguientes hipótesis:

H1. Pese a iniciativas desde algunos medios y los estudios que se están empezando a desarrollar desde el ámbito académico, no existe un estándar para la construcción de una narrativa para contenidos periodísticos de carácter inmersivo. 
H2. A partir de los testimonios experienciales de los 60 jóvenes encuestados, se pueden conocer aspectos del hábito del consumo digital de este segmento, lo cual puede arrojar pistas para desarrollar contenidos de carácter inmersivo más exitosos y con mayor engagement.

H3. A partir de los resultados obtenidos en las encuestas, así como a través de los grupos de discusión, pueden surgir eventualmente nuevos hábitos o escenarios de consumo audiovisual no considerados hasta el momento por parte de los productores de contenidos noticiosos e informativos en formato $360^{\circ}$ con capacidad inmersiva.

H4. Y como resultado de este estudio, aproximarnos o hacer el intento de establecer las bases de un modelo narrativo inmersivo y de realidad virtual enfocado en el periodismo.

\section{Metodología}

Con el fin de intentar cumplir con los objetivos de la investigación, así como dar resolución a las hipótesis planteadas, se ha optado por la realización de un estudio mixto, donde el elemento cuantitativo está compuesto por encuestas de once preguntas, realizadas a 60 alumnos de las facultades de periodismo de la Generación Z (Turner, 2015) de la Comunidad de Madrid y CastillaLa Mancha.

El tamaño de la muestra va en sintonía con estudios relacionados con la misma tecnología y similar estilo narrativo (Aardena et al., 2010; Aitamurto, 2018; Hendriks et al., 2019; Jones, 2017; Matsangidou et al., 2019 y Steed et al., 2018).

El aparente sesgo de los implicados en la muestra, corresponde a elementos meramente prácticos para efectos del desarrollo de la experimentación (tomamos como referencia el estudio de CaseroRipollés, Izquierdo-Castillo y Doménech-Fabregal, 2016) y porque nos resultaba de interés conocer la apreciación de estudiantes que apenas se están iniciando en la carrera y no tienen aún criterios profesionales para opinar sobre este tipo de contenidos, siendo así una visión amateur como la de cualquier espectador común.

En un futuro resultará de interés comparar estas apreciaciones con los criterios que hayan forjado al haber culminado los estudios de periodismo. Y aunque otros implicados hayan estado en cursos por delante, como señalan Feixa, Fernández-Planells y Figueras-Maz (2016) esa hiperdigitalización e interconexión de los jóvenes actuales a veces impera más que cualquier concepción profesional.

Los vídeos considerados para dicho instrumento de medición, obedecen a la temática específica de la crisis humanitaria que atraviesa Venezuela sobre la cual, uno de los contenidos está realizado por una ONG sin ningún criterio de producción y de una forma claramente amateur; y el otro, en contraste, está producido por un reconocido medio de comunicación internacional, en el cual recurren a diversos elementos de interacción para ampliar la información proporcionada.

Esta temática fue considerada por tratarse de un tema con enormes posibilidades de generar engagement por parte de la audiencia, por tratarse de un problema actual y ampliamente cubierto por medios internacionales. Por esta misma condición, existen contenidos de carácter inmersivo de diferentes calidades y criterios de producción, lo cual ofrecía para los efectos de la presente investigación, los recursos necesarios para recabar los datos deseados. 
La visualización de los contenidos por parte de los usuarios participantes, se realizó mediante visores genéricos de realidad virtual para dispositivos móviles, es decir, los participantes dispusieron de sus propios smartphones para la ejecución de la actividad.

Hacia un modelo idóneo de narrativa en periodismo inmersivo

A partir de los vídeos "Desabastecimiento y escasez en Venezuela"(https://youtu.be/g7JoglmZJXo) "Agony in a venezuelan mental heatlh hospital" (https:/lyoutu.be/UIN g69uYPA) conteste por favor las siguientes preguntas:

*Obligatorio

¿Has tenido antes alguna experiencia de visionado de contenidos multimedia en $360^{\circ}$ con capacidad inmersiva?

$\square$ Sí

$\square$ No

Señala el nivel de inmersión (sentirse parte de la historia) experimentado al ver el contenido CON elementos informativos adicionales (textos, narración en off, etc.) *

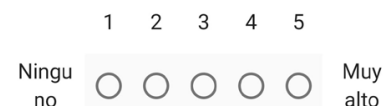

Este formato te invita a implicarte más en los contenidos que se te presentan

$\square$ Sí
$\square$ No

Cuál de estos elementos orientativos consideras imprescindibles para una experiencia inmersiva, narrativamente hablando

Textos

Voz en off

Música

Sonido ambiente

Llamados de atención (gráficos)

Consideras que es importante que haya un orden correlativo entre escenas

$\square$ Sí

$\square$ No
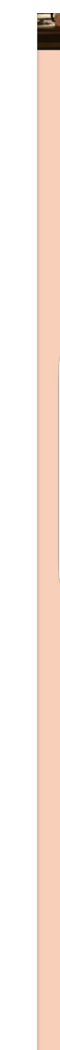

Señala el nivel de inmersión (sentirse parte de la historia) experimentado al ver el contenido SIN elementos informativos adicionales (textos, narración en off, etc.) *

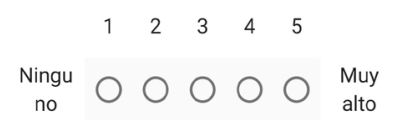

Narrativamente, el cambio entre escenas te resulta más inmersivo

$\square$ Una transición suave entre planos

$\square$ Por corte

$\square$ Una animación

La necesaria interacción visual con los contenidos y la libre dirección de la mirada, te resulta narrativamente más atractivo $\mathrm{e}$ inmersivo que otro tipo de contenidos multimedia

$\square$ Sí

$\square$ No

Desde la experiencia inmersiva, dada la imposibilidad de realizar planos detalle-zoom, crees conveniente que en momentos puntuales, aparezca una imagen convencional superpuesta en el plano

$\square$ Sí

$\square$ No

Consideras que mostrar el trípode en el visionado inmersivo altera la imagen y es irrelevante, 0 mostrarlo en una seña de transparencia en contenidos periodísticos

$\square$ sí

$\square$ No

Para consumir inmersivamente los contenidos resulta mejor:

Planos en movimiento

Planos estáticos

Imágenes 1, 2, 3 y 4: modelo de encuesta sobre el visionado de dos contenidos con capacidad inmersiva, disponibles en YouTube. Fuente: Google Forms. 
Con la intención de obtener mayor profundidad en el resultado de algunas respuestas del cuestionario, se realizaron dos grupos de discusión con enfoque exploratorio (Calder, 1977), compuestos por 5-6 individuos correspondientes al mismo contexto planteado para los otros instrumentos de medición.

El perfil de los participantes, similar a los de la encuesta, corresponde a estudiantes del Grado en Periodismo en las universidades de Castilla-La Mancha (Cuenca) y Francisco de Vitoria (Madrid).

Se optó por conformar un grupo de Castilla-La Mancha y otro de Madrid, cuyos participantes tuvieron la oportunidad de apreciar los dos vídeos tratados, de manera inmersiva y de forma individual. Una vez que todos pudieron consumir ambos, fueron reunidos en una sala dispuesta para la discusión.

En todo momento la actividad fue supervisada y mediada por los investigadores. En la sesión de discusión en grupo, uno de los investigadores fungió de conductor.

La experimentación realizada por Casero-Ripollés, Izquierdo-Castillo y Doménech-Fabregal (2016) y Jones (2017) fueron referenciales para esta actividad. Consideramos esta técnica como la más apropiada, por permitirnos contar con un método de exploración que permite a los participantes expresar sus preocupaciones u opiniones dentro de un contexto (Zeller y Carmines, 1980), lo cual resulta útil para los fines de la presente investigación. Las preguntas realizadas en este ejercicio fueron:

- Cuando consumimos contenidos con visores de realidad virtual, en definitiva ¿son molestos elementos adicionales como textos o gráficos, o por el contrario contribuyen a una mayor comprensión de lo allí mostrado?

- ¿Estos elementos son más convenientes en el formato semiinmersivo?

- ¿Consideran que la voz en off es un elemento que ayuda a guiarnos por el contenido, o por el contrario interfiere con la experiencia?

- ¿Si se elimina el trípode como muchos han señalado, no consideran que se vulnera la transparencia del contenido, al estar editado?

- En el modo de visionado inmersivo, es decir, mediante el uso de visores de VR ilos movimientos de cámara generan mareos $\mathrm{o}$,

- por el contrario, no resultan desagradables para la experiencia?

Asimismo, se tomó en consideración un análisis comparativo entre los resultados obtenidos, así como un análisis comparativo entre la narrativa inmersiva y la narrativa audiovisual tradicional, con la finalidad de intentar llegar a un modelo narrativo estándar en realidad virtual o audiovisual de carácter inmersivo.

\section{Resultados}

De la encuesta realizada a 60 individuos correspondientes a la Generación $Z$ (Turner, 2015) de las comunidades autónomas de Madrid y Castilla-La Mancha (España) obtuvimos los siguientes datos: 


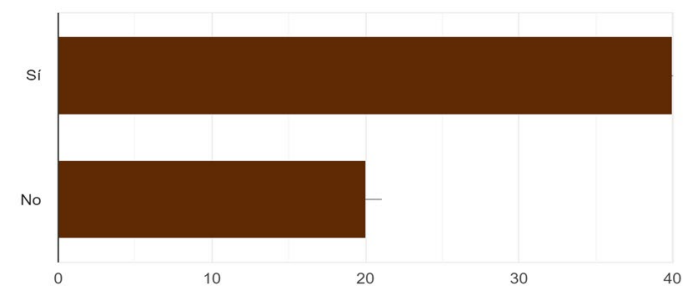

Gráfico 1: ¿Has tenido antes alguna experiencia de visionado de contenidos multimedia en $360^{\circ}$ con capacidad inmersiva?

Fuente: Google Forms a partir de encuesta realizada.

Del universo encuestado, el $66,7 \%$ afirmó que ya había experimentado con anterioridad con esta tecnología, un dato importante para establecer un criterio en cuanto a demanda y gustos sobre este tipo de contenidos, ya que la novedad y la sorpresa podían condicionar las respuestas a resultados no tan fiables.

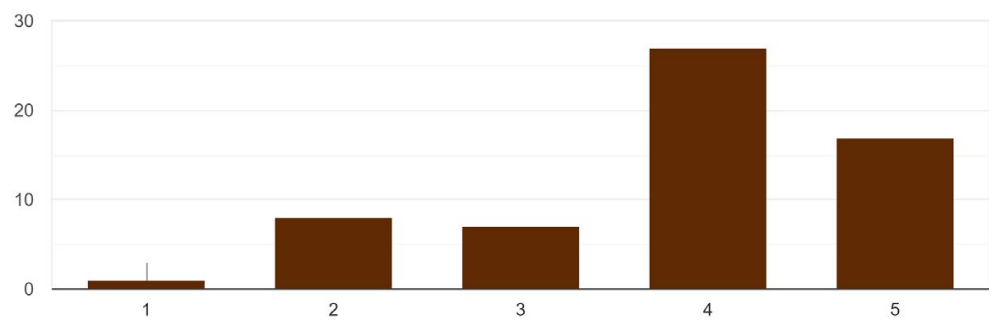

Gráfico 2: señala el nivel de inmersión (sentirse parte de la historia) experimentado al ver el contenido CON elementos informativos adicionales (textos, narración en off, etc.)

Fuente: Google Forms a partir de encuesta realizada.

La mayoría de los usuarios señaló como "alto" y "muy alto" el nivel de inmersión alcanzado con el contenido No.2, correspondiente a la cobertura realizada por The New York Times en un hospital psiquiátrico venezolano.

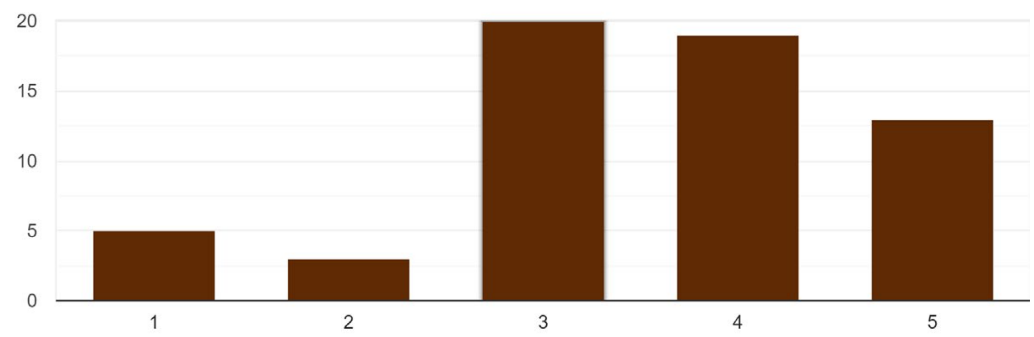

Gráfico 3: señala el nivel de inmersión (sentirse parte de la historia) experimentado al ver el contenido SIN elementos informativos adicionales (textos, narración en off, etc.).

Fuente: Google Forms a partir de encuesta realizada.

Con el contenido No.1, correspondiente a la ONG venezolana Redes, los usuarios indicaron que el nivel de inmersión bajó un poco ante la ausencia de información adicional. 


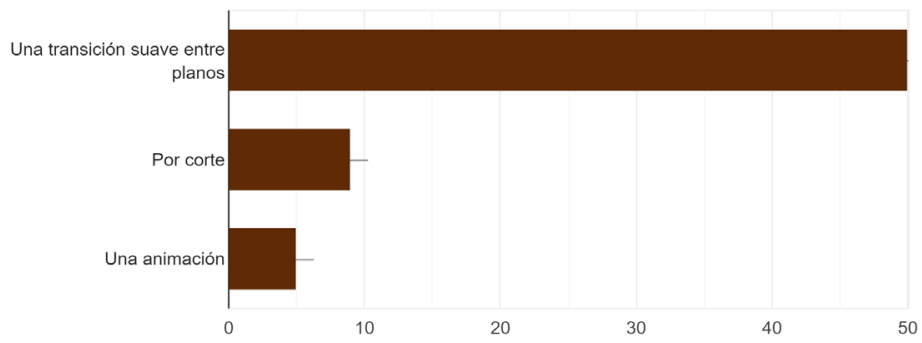

Gráfico 4: narrativamente, el cambio entre escenas te resulta más inmersivo.

Fuente: Google Forms a partir de encuesta realizada.

La mayoría optó por señalar las transiciones suaves entre escenas y planos como la mejor opción en el modo de visualización inmersivo.

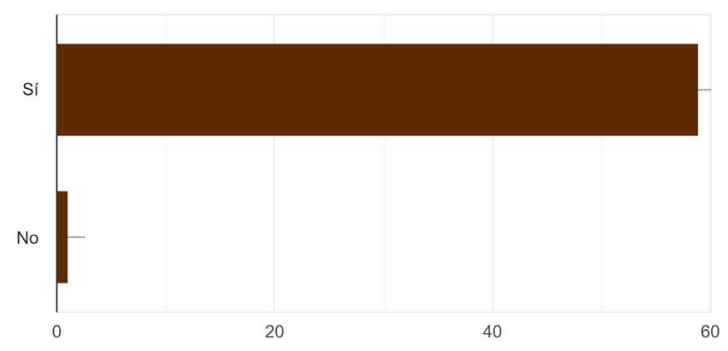

Gráfico 5: la necesaria interacción visual con los contenidos y la libre dirección de la mirada, te resulta narrativamente más atractivo e inmersivo que otro tipo de contenido multimedia.

Fuente: Google Forms a partir de encuesta realizada.

El $98,3 \%$ de los encuestados consideró que los contenidos con capacidad inmersiva son más atractivos que otro tipo de contenido multimedia.

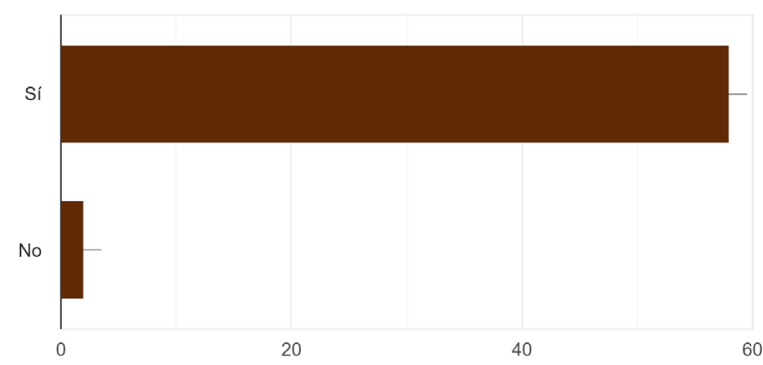

Gráfico 6: este formato te invita a implicarte más con los contenidos que se te presentan.

Fuente: Google Forms a partir de encuesta realizada.

En cuanto al concepto de inmersión, la mayoría $(96,7 \%)$ cree que se trata de un formato que implica mucho más al usuario con respecto al contenido. 


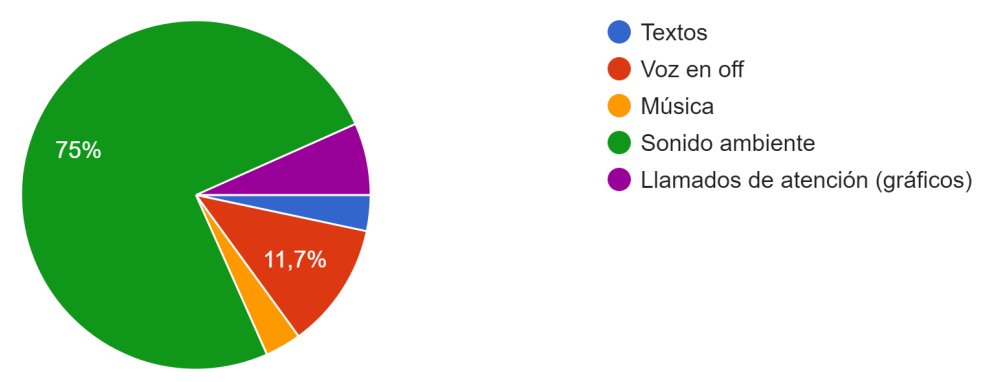

Gráfico 7: ¿Cuál de estos elementos orientativos consideras imprescindibles para una experiencia inmersiva, narrativamente hablando?

Fuente: Google Forms a partir de encuesta realizada.

El 75\% de los encuestados considera que el sonido ambiente, es decir, el sonido original de la cobertura realizada, es imprescindible para alcanzar mayor inmersión con respecto al contenido presentado. Asimismo, muy lejos de esa cifra, con $11,7 \%$, se ubica la voz en off como segundo recurso aceptado para ampliar la información mostrada.

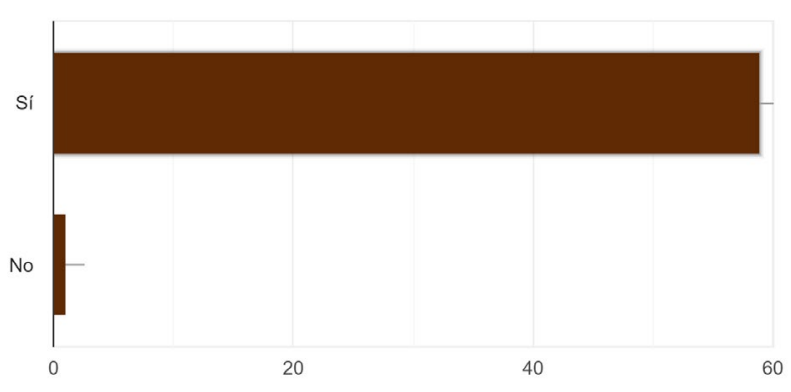

Gráfico 8: ¿Consideras que es importante que haya un orden correlativo entre escenas?

Fuente: Google Forms a partir de encuesta realizada.

Indudablemente, la mayoría considera que debe haber un orden coherente en la sucesión de planos y escenas en los contenidos con carácter inmersivo.

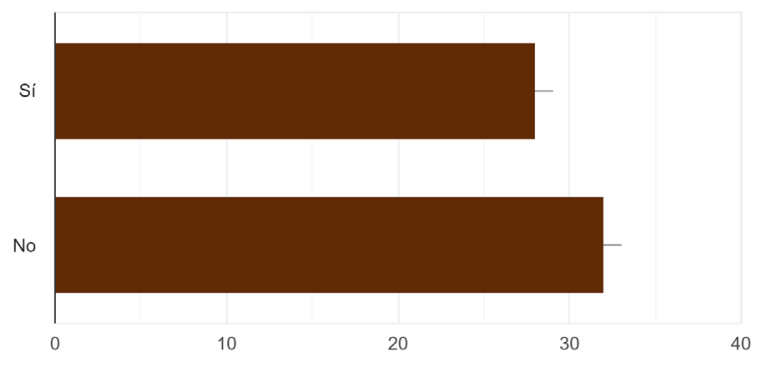

Gráfico 9: desde la experiencia inmersiva, dada la imposibilidad de realizar planos detalle-zoom ¿crees conveniente que, en momentos puntuales, aparezca una imagen convencional superpuesta en el plano?

Fuente: Google Forms a partir de encuesta realizada. 
Si bien se trata de un recurso tomado en consideración por algunos medios en la creación de piezas periodísticas en este formato, la mayoría del universo encuestado en la presente investigación $(53,3 \%)$ no cree conveniente recurrir a ello como un elemento informativo.

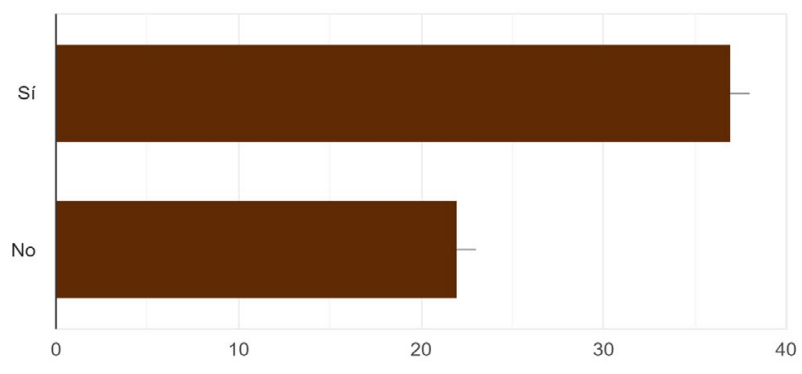

Gráfico 10: ¿Consideras que mostrar el trípode en el visionado inmersivo altera la imagen y es irrelevante, o mostrarlo es una seña de transparencia en contenidos periodísticos?

Fuente: Google Forms a partir de encuesta realizada.

Para la mayoría (62,7\%), que aparezca el trípode que sostiene la cámara en $360^{\circ}$ resulta un elemento de distorsión y molesto a la hora de visualizar inmersivamente el contenido.

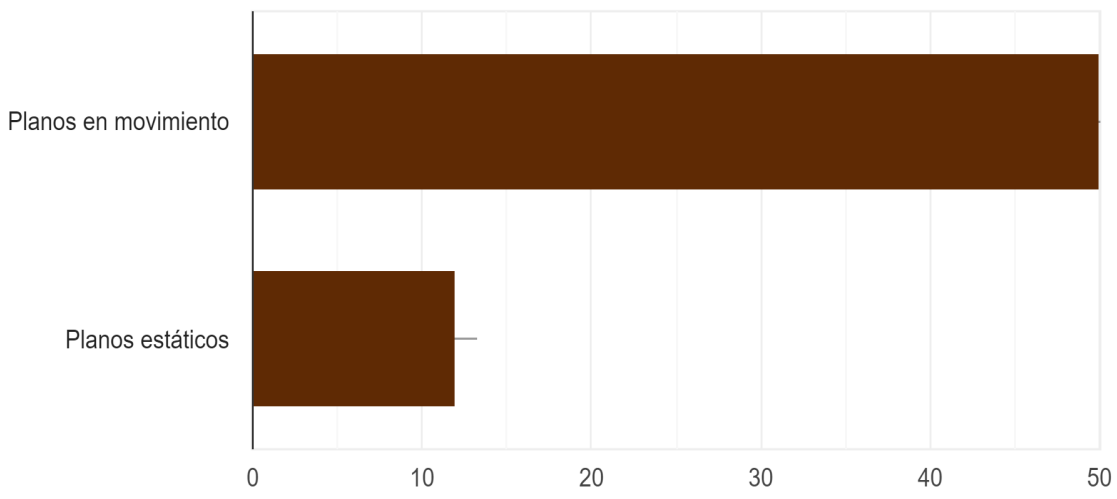

Gráfico 11: ¿Para consumir inmersivamente los contenidos resulta mejor planos en movimiento o estáticos?

Fuente: Google Forms a partir de encuesta realizada.

El 83,3\% se inclinó por la propuesta estética del vídeo No.1 (ONG Redes) en constante movimiento, en comparación a la propuesta de cobertura de The New York Times en el vídeo No.2, compuesto por una consecución de planos estáticos con el libre albedrío por parte del usuario, característico del formato inmersivo en $360^{\circ}$.

Como ya indicamos con anterioridad, al haber algunas respuestas que no permitían determinar en definitiva la preferencia sobre algunos aspectos que deben tener los contenidos inmersivos de índole periodístico, se realizaron dos grupos de discusión con los siguientes resultados:

Ante la pregunta cuando consumimos contenidos con visores de realidad virtual, en definitiva ¿son molestos elementos adicionales como textos o gráficos, o por el contrario contribuyen a una mayor comprensión de lo alli mostrado? el grupo 1 (alumnos de la UCLM http://bit.ly/FGalumnosUCLM) 
aseguró que ayudan a comprender lo que se muestra, son un elemento más del contenido pese a que al principio pueden generar algo de incomodidad. Al respecto, en el grupo 2 (alumnos de la UFV http://bit.ly/FGalumnosUFV) aseguraron que los textos estorban, ya que al instar a ser leídos por el usuario, generan pérdida de atención con respecto al contenido reproducido. También depende de la intención del vídeo, es decir, resulta preferible colocar información escrita al inicio o al final del contenido, evitando superponerlo a la imagen durante la reproducción. El hecho de que aparezcan durante el vídeo puede generar un retroceso en el proceso de inmersión por parte del usuario.

En cuanto a que, si estos elementos resultaban más convenientes en el formato semiinmersivo, el grupo 1 consideró por unanimidad que no, y que era preferible contar con ellos en el modo de visualización inmersivo. No obstante, el grupo 2 añadió el hecho de que debe procurarse que el contenido audiovisual hable por sí solo y recurrir a los textos o elementos informativos solo de ser estrictamente necesario para la comprensión de lo mostrado, dado que la comprensión del texto requiere funciones cognitivas adicionales por parte del usuario, lo cual le resta atención con respecto al contenido audiovisual.

Con respecto a si consideraban que la voz en off resulta un elemento de ayuda en la vehiculación por el contenido, o por el contrario interfiere con la experiencia, el grupo 1 señaló que no puede ser un elemento constante, pues debe imperar el audio original de la grabación. Las narraciones explicativas deben ser intermitentes y en algunos casos, alternadas con algunos textos no invasivos. Bajo ningún concepto la narración en off debe aludir a datos insertos en eventuales textos o llamadas de atención en el contenido. Para el grupo 2, este recurso resulta de ayuda siempre y cuando añada elementos adicionales a lo que se ve. Debe estar en definitiva alternado con el audio original del contenido que asegura la sensación de inmersión.

Para la pregunta ¿si se elimina el trípode como muchos han señalado, no consideran que se vulnera la transparencia del contenido, al estar editado? el grupo 1 consideró que bajo ningún concepto debe verse algún rastro del trípode, dado que en la visualización inmersiva resulta molesto ver cualquier indicio del soporte de la cámara en contenidos del tipo RVR. Por su parte, el grupo 2 fue unánime al señalar que el trípode es indiferente y que, por tanto, da igual que se vea o no parte de él.

Por último, al ser consultados sobre si en el modo de visionado inmersivo, es decir, mediante el uso de visores de VR ¿los movimientos de cámara generan mareos o, por el contrario, no resultan desagradables para la experiencia? el grupo 1 por unanimidad se decantó por el hecho de que, si bien el movimiento en los vídeos consumidos de manera inmersiva podían generar un poco de incomodidad al principio de su reproducción, no cuesta mucho acostumbrarse. A su criterio, esta forma de grabar es preferible porque da mayor sensación de realismo. La temática es por igual importante, con lo cual, el movimiento será siempre menos molesto mientras la historia presentada resulte de gran interés para la audiencia. Al respecto, el grupo 2 consideró que los vídeos en movimiento dan una mayor sensación de realismo, sin quitar el hecho que puedan generar mareo eventualmente, siendo lo ideal, una alternancia entre planos en movimiento y escenas estáticas.

\section{Discusión y conclusiones}

Ha sido un aspecto a favor de nuestra investigación que el universo de participantes en el instrumento de medición, así como en las dinámicas grupales de discusión, fuesen en mayoría individuos que ya habían tenido un acercamiento previo a esta tecnología, tal y como se refleja en el gráfico 1. 
Si bien aún existe una carencia de estudios en el ámbito de la comunicación y el periodismo, sobre los modelos narrativos en realidad virtual más inmersivos y que generan más engagement y empatía con los contenidos presentados de la "Generación Z", de las encuestas realizadas podemos concluir que este segmento de la audiencia prefiere que los contenidos multimedia con capacidad inmersiva estén producidos:

- Con transiciones suaves entre planos y escenas

- Con predominio del sonido ambiente, original de la toma (en el caso de producciones en RVR), así como con voz en off, que explique o destaque algunos detalles de consideración en el contenido mostrado.

- Con un orden correlativo entre escenas y planos, es decir, que exista coherencia en la propuesta narrativa.

- Sin imágenes convencionales eventualmente superpuestas con el fin de destacar detalles en el contenido inmersivo.

- Sin rastros del trípode (en el caso de producciones en RVR)

- Con escenas o planos en movimiento.

Al contrastar algunos de estos resultados con los datos recabados en las dinámicas grupales, podemos agregar que:

- El uso del recurso de textos adicionales debe minimizarse al máximo, y, por tanto, debe ser lo menos invasivo posible con respecto a la imagen. Preferiblemente debe recurrirse a ello al principio o al final de la producción.

- El recurso de la voz en off es pertinente, pero debe ser intermitente, procurando que el audio original de la toma (en producciones en RVR) sea lo que predomine. Se debe procurar su uso para puntualizar aspectos o detalles muy específicos, sobre todo de contextualización.

- Pese a no haber un consenso sobre la eliminación de vestigios del trípode (en producciones en RVR), no es considerada su edición un indicio de vulneración del contenido y dicha labor puede entenderse como una acción secundaria en el proceso de postproducción.

- Los planos o escenas en movimiento dan sensación de mayor realismo en la experiencia de consumo inmersivo, no obstante, planos o escenas estáticas son convenientes por igual, pero de manera intercalada, en la producción de vídeos con estas características.

Si bien la extensión de los contenidos no fue un elemento tomado en consideración para los fines de este estudio, pareciera no resultar un detalle importante si tomamos en consideración que el vídeo 1, producido por la ONG venezolana Redes, tiene una extensión de 1 minuto 53 segundos, y el vídeo 2, correspondiente a The New York Times, 3 minutos 30 segundos.

Al margen de los objetivos propuestos, de las encuestas también podemos evidenciar que, para la mayoría de los participantes, los contenidos multimedia con capacidad inmersiva resultan más atractivos desde la propuesta narrativa, que los contenidos realizados en formato convencional. Esto por supuesto, no propone la sustitución de un formato por otro, sino que invita a considerar estas posibilidades de cara a temas específicos donde resulte necesario, generar mayor interacción y acercamiento por parte del público.

En este orden, existe un consenso como bien se ilustra en el gráfico 6, en el hecho que los contenidos multimedia con capacidad inmersiva invitan a la audiencia a implicarse más con el tema que se plantee a través de ellos, con lo cual, se trata sin duda alguna de una herramienta con un enorme 
poder de vinculación entre público y contenido, por ejemplo, de cara a la cobertura de temas sociales e inclusive de carácter político.

Si bien en este sentido, las investigaciones de Hendriks et al. (2019) y Shin y Biocca (2018) son bastante determinantes, se aprovechó la disposición de los implicados en el presente experimento, para ratificar este aspecto teniendo en consideración la disposición geográfica (España) y el grupo etario (Generación Z) contrastantes.

La interpretación de los resultados descritos nos lleva, claramente, hacia unos estándares de consumo que nos conducen a cumplir el objetivo principal de la presente investigación, proponer un estándar o modelo de narrativa de realidad virtual plenamente inmersivo $\mathrm{y}$, con ello, contribuir a que se inserte en los hábitos de consumo cotidiano de contenidos audiovisuales, sumando mayor engagement de los mismos. Asimismo, nos lleva a aportar a la comunidad científica y profesional, una serie de aspectos básicos a cumplir en el diseño y producción de los contenidos.

Con la intención de mejorar los resultados del primer objetivo nos propusimos un segundo, y fue realizar una comparativa entre la narrativa audiovisual de los medios analógicos y la narrativa de realidad virtual y los formatos con capacidad inmersiva, con la intención de poner en evidencia la necesaria transformación de aquella, así como la necesidad de generar entre toda la comunidad científica y profesional (y estas prácticas contribuyen a ello) manuales con normativas y guías para la concepción, diseño, realización y producción de contenidos en virtuales e inmersivos. Esta comparativa también nos proporciona qué elementos son aún válidos de la narrativa audiovisual tradicional en cuanto a nuestra forma de ver y mirar, y cuáles deben transformarse y/o adaptarse.

Partimos de una primera premisa fundamental, el carácter inmerisvo de los formatos en realidad virtual son inmersivos en sí por el mero hecho de ser contenidos en $360^{\circ}$, puesto que que se asemejan, esencialmente, a nuestra forma de ver. De ahí que los resultados del estudio planteado muestren que son contenidos más atractivos y que les acercan más a los hechos narrados.

A partir de aquí, en relación a la interpretación de los resultados obtenidos, podemos observar que se dan diferentes grados de inmersión en relación al modelo narrativo planteado, que tiene que ver con el hecho de que la ideación de esos contenidos, su grabación, realización y producción están concebidos desde un pensar en realidad virtual y $360^{\circ}$ o si se hace desde una visión de narrativa analógica.

Efectivamente, como hemos afirmado, un formato en realidad virtual en $360^{\circ}$ es inmersivo por el mero hecho de estar en $360^{\circ}$, tal como nosotros vemos, pero si concebimos su ideación, grabación, realización y producción desde la mirada analógica, fracasaremos en nuestro modelo de inmersión. Y eso tiene que ver directamente con que el cambio y transformación que supone el formato de realidad virtual $360^{\circ}$ respecto a la narrativa tradicional, es que se rompe frontalmente con su unidad básica de significado, el plano.

El plano salta por los aires para convertirse en múltiples planos y múltiples miradas, tantas como el consumidor de estos contenidos quiera navegar a partir del plano $360^{\circ}$ prediseñado por el creador de dichos contenidos. Entramos en la cuarta dimensión, en la misma medida que Picasso rompió radicalmente la perspectiva lineal (el 2D), para pasar con el cubismo a la cuarta dimensión (una propuesta conceptual de 3D en el formato estático de la pintura, en una dimensión meramente espacial).

Ahora tenemos la posibilidad de ampliar esta experiencia con la dimensión que permite el lenguaje audiovisual, el tiempo, el movimiento. Así bien, teniendo presente, que con estos formatos pasamos 
de tener un número concreto de planos y angulaciones (plano general, medio, contrapicado, etc.), ahora disponemos de un plano un único plano, el plano de $360^{\circ}$ o panorama (Oliver, 2017), con múltiples planos y/o miradas, que deben ser prediseñadas por el creador de dichos contenidos.

De acuerdo al estudio de Oliver (2017) El color del sol. Narrativa Audiovisual y Realidad Virtual, el pre-diseño de los contenidos a elaborar debe de estar determinado por diferentes niveles de atención, uno principal en el que se desarrolle la acción y que conduzca la mirada del espectador hacia esa dirección, y otros secundarios que se encuentre el espectador en su propia navegación y elección de encuadre, y que refuercen el punto de interés principal sin que se pierda en esa navegación.

Una vez establecida la premisa de que el principal hecho rompedor es del plano como unidad básica en los formatos analógicos a un "panorama" como plano único, el diseño narrativo en cuanto modos de lectura implicados en el lenguaje audiovisual en el sentido de su capacidad de inmersión y de empatizar con los contenidos, guarda bastantes similitudes con la narrativa tradicional, en relación a los resultados arrojados del estudio.

El orden correlativo y coherente entre planos y escenas para vehicular la dirección de nuestra mirada, apunta directamente a nuestra forma de lectura del formato audiovisual tradicional y a la base fundamental de la construcción del relato en dicha narrativa. Tiene que ver con el raccord o continuidad. En el caso de los formatos de realidad virtual tenemos que hablar de stitching o cosido para lograr esa continuidad y conducción de la mirada.

Por otro lado, para lograr mayor inmersión o mimetización de nuestra forma de ver (que es lo que logra la inmersión primaria) se requieren más planos en movimiento. Este aspecto es absolutamente similar a la cámara en mano en la narrativa tradicional cuando el director quiere desmantelar, en algún grado, la artificiosidad de la lente cinematográfica como intermediadora entre la historia que quiere narrar y el espectador, poniendo énfasis a la cotidianidad de la escena que se muestra (pensemos, por ejemplo, en numerosas películas de Woody Allen). Al igual que en estas escenas para no desequilibrar en exceso la mirada del espectador se intercala con planos estáticos. Básicamente, este es el aspecto al que apuntaban los encuestados en relación al uso de planos en movimiento.

Por último, en relación a otros elementos narrativos analizados y sobre los que les hemos preguntado a los jóvenes sometidos a estudio, sucede algo similar. La inclusión de texto y/o imágenes adicionales solo debe hacerse con carácter excepcional, para lograr un mayor realismo y/o inmersión.

Asimismo, el hecho de que aparezcan elementos propios técnicos del proceso de grabación como el trípode, salvo excepciones en el cine como el Movimiento Dogma 95, la aparición de estos aparatos nada tiene que ver con el realismo y/o cotidianidad de las escenas mostradas, sino más bien como un elemento distorsionador en la inmersión de la historia. Igual sucede, como hemos comprobado de los resultados obtenidos, en la realidad virtual $360^{\circ}$.

Y en esa misma dirección está el uso del sonido, que su inclusión resulta un elemento exponencialmente inmersivo tanto para los relatos en formato tradicional como en los formatos inmersivos de realidad virtual.

\section{Conclusiones}

La disparidad evidente en algunas respuestas, sobre todo si comparamos los dos grupos participantes en las sesiones de discusión, deja en evidencia la amplitud de criterio y gustos que existe en las 
audiencias, lo cual es una de las principales características del profundo y acelerado proceso de segmentación de públicos como consecuencia de la revolución digital.

Independientemente que los individuos pertenezcan al mismo segmento, misma generación, e inclusive mismo nivel socio-económico, las preferencias en relación a los contenidos son cada vez mayores y diferentes, lo cual complejiza el proceso de creación y producción por parte de los responsables de generarlos, en el caso particular de esta investigación, de periodistas y medios.

Las encuestas realizadas, así como las dinámicas grupales con jóvenes audiencias españolas han permitido disponer de algunos elementos básicos para la creación de contenidos noticiosos en formatos multimedia con capacidad inmersiva, con base a las experiencias directas de los usuarios.

Es indudable que debe existir mayor compromiso por parte de los medios y los periodistas por innovar y, sobre todo, por concienciar en definitiva acerca del alcance sin retorno de este formato, especialmente en España.

Existe la demanda, existe el interés, pero el proceso de desarrollo e innovación periodística no pareciera ir de la mano, pese a la existencia de media docena de laboratorios de innovación en España (López y Ufarte, 2016; Salaverría, 2015) siendo el de El País, el de más reciente creación, a finales del primer trimestre de 2018.

En ese sentido, pensamos que el presente estudio es una importante aportación a esos laboratorios para proporcionarles un modelo de narrativa de realidad virtual $360^{\circ}$ inmersiva y que permita consolidar el consumo de estos contenidos en el contexto de nuestro estudio, el periodismo. Las conclusiones arrojadas en relación a la interpretación del resultado de las encuestas y los grupos de discusión lo muestran. Qué patrones narrativos seguir en relación a nuestro modo de leer la imagen audiovisual y de consumo de estos formatos inmersivos.

Por otro lado, en el caso de El País, así como RTVE, que vienen produciendo de manera periódica experiencias en realidad virtual y coberturas informativas en $360^{\circ}$ con capacidad inmersiva, aunque esto corresponda al desarrollo de otra investigación, consideramos que debe haber mayor promoción de estos contenidos, así como su clasificación aparte de las secciones multimedia, como lo ha hecho El Deporte Conquense (véase http://eldeporteconquense.com/category/360o/), desde la categoría del periodismo local, con el fin de no solo fomentar su consumo, sino para poder llegar a la mayor cantidad de audiencia posible y darle la visibilidad necesaria a contenidos más interactivos y con perspectivas diferentes a los formatos tradicionales.

Ya advierten Pérez-Seijó et al. (2018) que en el caso de medios públicos europeos que producen contenidos noticiosos con carácter inmersivo, solo el 29,63\% cuenta con una sección específica para organizar y promocionar este tipo de contenidos,

Hablamos de un recurso imprescindible al día de hoy de cara a estrategias para incrementar la difusión de temas y coberturas noticiosas, que en el ámbito periodístico goza de gran aceptación en medios internacionales, consolidado como un formato más en su oferta informativa, y que por tanto, no solo requiere de una mayor promoción, sino de un esquema o requerimientos básicos de producción y postproducción para asegurar una mayor distribución, así como mayor engagement, en audiencias que no acuden a los medios y las noticias por los canales tradicionales, así como proporcionar una perspectiva diferente del hecho noticioso a los usuarios que desean ampliar su conocimiento al respecto. 
Finalmente, consideramos que, con lo expuesto en relación a la interpretación de los datos, estamos en disposición de afirmar que hemos logrado, de forma aproximativa, una propuesta de narrativa multimedia con capacidad inmersiva y de realidad virtual en el medio periodístico.

Como último apunte, surge como nueva reflexión el hecho de que no tenemos aún suficientes herramientas, estudios y/o argumentaciones para determinar si las similitudes que hemos hallado entre los modos de lectura entre un modelo de narrativa y otro tienen que ver con que nuestros modos de lectura de la imagen audiovisual están condicionados por nuestra educación audiovisual y una mirada educada y formada en las décadas que nos preceden de narrativa audiovisual del contexto digital o no. Es decir, si solo es cuestión de que en las próximas décadas se formatee nuestro modo de ver (nuestra mirada como cuestión cultural, damos por hecho que sí) y debamos reescribir los modelos aquí propuestos.

\section{Referencias bibliográficas}

Aardena, F., O'Connor, K., Côté, S. \& Taillon, A. (2010). Virtual reality induces dissociation and lowers sense of presence in objective reality. Cyberpsychology, behavior and social networking, 13(0), 1-8. http://dx.doi.org/10.1089/cpb.2009.0164

Aitamurto, T. (2018). Normativw paradoxes in $360^{\circ}$ journalism: contested accuracy and objectivity. New media \& Society, 1-17. http://dx.doi.org/10.1177/1461444818785153

Cantero, J. I.; Sidorenko, P. y Herranz, J. M. (2018). Realidad virtual, contenidos $360^{\circ}$ y periodismo inmersivo en los medios latinoamericanos. Una revisión de su situación actual. Contratexto, 29, 73-103. http://dx.doi.org/10.26439/contratexto2018.n029.1816

Calder, B. J. (1997). Focus group and the nature of qualitative marketing research. Journal of marketing research, Vol. XIV, 353-364.

Calvo, L. M. (2018). Twitter como segunda pantalla en los debates políticos en televisión. Icono 14, $16(1), 160-184$.

Cardoso, G. (2014). Movilización social y medios sociales. Vanguardia Dossier, 50, 16-23.

Casero-Ripollés, A., Izquierdo-Castillo, J. y Doménech-Fabregat, H. (2016). The Journalists of the Future Meet Entrepreneurial Journalism. Journalism Practice, 10:2, 286-303.

Castells, M. (2010). Comunicación y poder. Alianza Editorial.

De la Peña, N. (2010). Immersive journalism: Immersive virtual reality for the first-person experience of news. Presence, MIT, 19(4).

Domínguez, E. (2013). Periodismo inmersivo. La influencia de la realidad virtual y del videojuego en los contenidos informativos. Editorial UOC.

Domínguez, E. (2010). Los nuevos formatos inmersivos y su aplicación en el periodismo. II Congreso Internacional de Ciberperiodismo y Web 2.0, Bilbao, 10-12 de noviembre del 2010.

Feixa, C., Fernández-Planells, A. y Figueras-Maz, M. (2016). Generación hashtag. Los movimientos juveniles en la era de la web social. Revista latinoamericana de Ciencias Sociales, Niñez y Juventud, 14(1), 107-120. 
Giddens, A. (1999). Runaway World: How Globalisation is Reshaping Our Lives. Profile Books.

Glickhouse, R. (2018, 12 de octubre). Chasing leads and herding cats: How journalism's latest job title - partner manager - works in ProPublica's newsroom. NiemanLab.

Hendriks V., P.; Wiltink, D.; Huiskamp, M.; Schaap, G. \& Katelaar, P. (2019). Taking the full view: How viewers respond to 360-degree video news. Computer in Human behavior, 91, 24-32.

Hopkins, M. (2017, 18 de octubre). Pioneering Virtual Reality and New Video Technologies in Journalism. New York Times.

Hjelm, J. (2000). Designing Wireless Information Services. John Wiley \& Sons.

Jarvis, J. (2015). El fin de los medios de comunicación de masas. Gestión 2000.

Jones, S. (2017). Disrupting the narrative: immersive journalism in virtual reality. Journal of Media Practice. http://dx.doi.org/10.1080/14682753.2017.1374677

Kakihara, M. (2003). Emerging Work Practices of ICT-Enabled Mobile Professionals. Information Systems. London School of Economics.

Longui, R. (2016). Narrativas imersivas no webjornalismo. Entre interfaces e realidad virtual. XIV Encontro Nacional de Pesquisadores em Jornalismo. Palhoça-Unisul, Brasil.

López H., A. y Ufarte R., M. J. (2016). Laboratorios de periodismo en España. Nuevas narrativas y retos de futuro. Ámbitos, 34, 1-12.

Matsangidou, M., Siang A., C., Mauger, A. R., Othmezuri, J. \& Avraamides, M. N. (2019). Is your virtual self as sensational as your real?. Virtual reality: the effect of body consciousness on the experience of exercise sensations. Psychology of sport and exercise, 41, 218-224. https://doi.org/10.1016/j.psychsport.2018.07.004

Manfredi, J. L. (2006). Servicio público y calidad en la televisión pública. Revista Andaluza de Administración Pública, 56, 275-297.

Manfredi, J. L. \& Artero, J. P. (2014). New business models for the media: the spanish case, en Psychogiopoulou, E. (Ed.) Media policies revisited. The challenge for media freedom and independence. Palgrave Macmillan.

Motta, L. G. (2005). Jornalismo e configuração narrativa da história do presente. Revista Contracampo, 12, 23-50.

Mütterlein, J. (2018). The Three Pillars of Virtual Reality? Investigating the Roles of Immersion, Presence, and Interactivity. Proceedings of the 51 $1_{\mathrm{st}}$ Hawaii International Conference on System Sciences 2018. 1407-1415.

Noguera V., J. M. (2018). Generación efímera. La comunicación de las redes sociales en la era de los medios líquidos. Comunicación Social ediciones y publicaciones. 
Oliver García, Javier (2017). El color del sol. Narrativa Audiovisual y Realidad Virtual Un cortometraje en $360^{\circ}$. Trabajo fin de Grado. Facultad de Comunicación. Universidad de Sevilla.

Paíno, A., Rodríguez, M. I., y Jiménez, L. (2016). El periodismo inmersivo y transmedia: de leer la historia a vivirla en primera persona. VII Congreso Internacional Latina de Comunicación Social, Universidad de La Laguna.

Pavlik, J. V. (2001). Journalism and New Media. Columbia University Press.

Pérez-Seijó, S., Melle G., M. y Paniagua R., F. J. (2018). Innovación en radiotelevisiones públicas europeas: narrativas inmersivas y organización de los contenidos $360^{\circ}$ en plataformas digitales. Revista Latina de Comunicación Social, 73, 1115-1173.

Pérez-Seijo, S. (2016). Origen y evolución del periodismo inmersivo en el panorama internacional. De los medios y la comunicación de las organizaciones a las redes de valor. Actas del II Simposio de la Red Internacional de Investigación de Gestión de la Comunicación.

Pontes, F. S. y Silva, G. (2010). Acontecimento jornalístico e história, en Benetti, M. y Fonseca, V. Jornalismo e Acontecimento: Mapeamentos críticos. Insular.

Pryor, L. (2000). Immersive News Technology: Beyond Convergence. USC Annenberg. Online Journalism Review.

Salaverría, S. (2018). Allá donde estés, habrá noticias. Cuadernos de periodistas, 35, 15-20.

Salaverría, S. (2015). Los labs como fórmula de innovación en los medios. El profesional de la información, 24(4), 397-404. http://dx.doi.org/10.3145/epi.2015.jul.06

Sánchez-Vives, M. V., y Slater, M. (2005). De la presencia a la conciencia a través de la realidad virtual. Nature Reviews Neuroscience, 6(4), 332. http://dx.doi.org/10.1038/nrn1651

Schwab, K. (2016). La Cuarta Revolución Industrial. Debate.

Shin, D. y Biocca, F. (2018). Exploring immersive experience in journalism. New media \& Society, 20(8), 2800-2823.

Sidorenko, P., Cantero, J. I., y Herranz, J. M. (2017). La realidad virtual y el formato multimedia en 360 como mecanismo de enriquecimiento de los contenidos periodísticos, en J. Sierra (Coord.), Nuevas tecnologías audiovisuales para nuevas narrativas interactivas digitales en la era multidispositivo (pp. 99-108). McGraw Hill Education; Universidad Camilo José Cela.

Slater, M. (2009). Place illusion and plausibility can lead to realistic behaviour in immersive virtual environments. Philosophical transactions of the Royal Society of London, 364(1535), 3549-3557.

Sørensen, C. (2003). Research Issues in Mobile Informatics: Classical Concerns, Pragmatic Issues and Emerging Discourses, en Proceedings of workshop on ubiquitouscomputing environment. Case Western Reserve University. 
Steed, A., Pan, Y., Watson Z. \& Salter, M. (2018). We wait - The impact of character responsiveness and self embodiment on presence and interest in an immersive news experience. Frontiers in robotics and AI, 5, 1-14. http://dx.doi.org/10.3389/frobt.2018.00112

Turner, A. (2015). Generation Z: Technology and social interest. The journal of individual Psychology, 71(2), 103-113.

Urry, J. (2000). Sociology beyond Societies: Mobilities for the Twenty-first Century. Routledge.

Vásquez Herrero, J., \& López García, X. (2017). Immersive Journalism through Mobile Devices: How Virtual Reality Apps Are Changing News Consumption, en A. Rocha et al. (Eds.), Recent Advances in Information Systems and Technologies (vol. 3, pp. 3-12). Springer.

Witt, L., Kperogi, F. A., Writer S. G., Bohrer, C., \& Negash, S. (2016). Journalism: How One University Used Virtual Worlds to Tell True Stories. ISOJ, 6(1).

Zeller, R. A. \& Carmines, E. (1980). Measurement in the Social Sciences: The Link Between Theory and Data. Cambridge University.

\section{AUTORES:}

\section{Raquel Caerols Mateo}

Acreditada como profesora Titular de Universidad por la ANECA y con un sexenio de investigación. Doctora en Creatividad Aplicada por la Facultad de Bellas Artes de la Universidad Complutense de Madrid (UCM). Profesora Adjunta en la Facultad de Comunicación de la Universidad Francisco de Vitoria en el área de creatividad. Además, ha participado como ponente en Congresos internacionales como el Computer Art en México DF, o el VI Congreso de lúdica y pedagogía. Por un nuevo aprender en Cartagena de Indias (Colombia). Cuenta con diversas publicaciones en prestigiosas publicaciones. Ha sido responsable de la dirección del I Simposio Cibercultura y New Media Art, financiado por el Ministerio de Cultura y Deporte del Gobierno de España.

r.caerols.prof@ufv.es

Índice $\mathrm{H}: 5$

Orcid ID: https://orcid.org/0000-0001-5167-8629

Google Scholar: https://scholar.google.es/citations?user=TP5S9WMAAAAJ\&hl=es

\section{Pavel Sidorenko Bautista}

Doctor por la Facultad de Periodismo de la Universidad de Castilla-La Mancha. Licenciado en Historia por la Universidad Central de Venezuela, con Maestría en Comunicación Social por la Universidad Católica Andrés Bello. Ha sido profesor en la licenciatura de Comunicación Social en la Universidad Monteávila de Caracas, en la Maestría de Comunicación Social de la Universidad Central de Venezuela y en el Grado en Periodismo de la UCLM. Investiga, escribe y dicta conferencias sobre redes sociales, nuevas narrativas y la aplicación del formato inmersivo y la realidad virtual en ámbitos como el periodismo, la publicidad y el marketing. Forma parte del proyecto de periodismo inmersivo E2C VR de la Facultad de Periodismo de la UCLM. Escribe en http://loft360.wordpress.com

Pavel.Sidorenko@alu.uclm.es

Î́ndice H: 2

Orcid ID: https://orcid.org/0000-0002-8094-3089

Google Scholar: https://scholar.google.es/citations?user=NZkQkeEAAAAJ\&hl=es 


\section{Pablo Garrido Pintado}

Doctor en Ciencias de la Información por la Universidad Complutense de Madrid con la tesis doctoral "Agencias de Viaje Online: Situación y perspectivas en el comercio electrónico español". Actualmente es profesor Contratado Doctor Acreditado por ANECA y Responsable de Innovación Docente en la Facultad de Comunicación de la Universidad Francisco de Vitoria. En los últimos 15 años, ha compaginado la docencia con su carrera profesional en el campo de publicidad y marketing digital. Durante varios años ha colaborado como profesional autónomo en el departamento de marketing digital de Tour Diez Travel, empresa situada en el top10 nacional de facturación turística. En su faceta investigadora es autor de artículos científicos y divulgativos y capítulos de libro en el campo de la publicidad, marketing turístico y creación audiovisual. Es miembro activo del grupo de investigación Icono 14. Cuenta con estancias como profesor visitante en la Universidad de La Haya (Holanda) y la Universidad San Pablo-T (Argentina).

p.garrido.prof@ufv.es

Índice H: 3

Orcid ID: https://orcid.org/0000-0001-7062-1855

Google Scholar: https://scholar.google.es/citations?user=6R2v8q0AAAAJ\&hl=es 